The two patients described in detail by Kilbridge and his colleagues showed the huge numbers of mycobacteria which are characteristic of the non-reactive form of tuberculosis seen in some cases of leukaemia. They extend the remarkable relationship between tuberculosis and the granulocytes ${ }^{4}$ to include mycobacteriosis. The importance of hypersensitivity in mycobacterial diseases and the disturbance of immunological responses in patients with abnormal function of their lymphocytes might suggest that peculiarities of mycobacterial infection would be a feature of lymphocytic disorders. In fact granulocytic disorders are much more commonly associated with non-reactive mycobacteriosis than are lymphocytic disorders. The granulocyte has traditionally been thought to play an insignificant role in the pathogenesis of mycobacterial infection. The relative frequency with which granulocytic abnormalities are intertwined with disseminated mycobacterioses suggests that this role might be profitably re-examined.

\section{Negligence and Doctors}

The decision of the courts in a case brought by a Somerset woman against her general practitioner ${ }^{1}$ gives rise for concern about the attitude they may adopt in future actions for negligence. Certain statements of law made in the Court of Appeal last week were well in line with earlier ones, but the application of the principles to the facts of the case is puzzling.

The patient claimed damages for negligence against her doctor after she had contracted fulminating septicaemia following normal delivery of a child in October 1963. The patient was aged 27. In August 1963 her fingers began to swell. On 4 October her wedding ring was filed off. At her last antenatal examination on 7 October she showed her doctor a reddened area about $\frac{1}{2}$ in. $(12.5 \mathrm{~mm}$.) in diameter within which there were three tiny spots, each with a yellow centre, under the site of the ring. The doctor told her not to worry about them. He took no steps to find out what organisms were causing the sepsis. On 11 October, the day after delivery of the child in a maternity home, a nurse noticed a reddened area on the patient's finger and found another reddened area on a toe which looked like a " shoerub." The patient was at once moved into a room on her own and the doctor was informed. He ordered a swab to be taken and sent to a pathological laboratory, and prescribed $250 \mathrm{mg}$. of tetracycline four times a day for five days.

In the days that followed the general picture was one of healing. On 15 October the finger and toe were both much improved, the finger more improved than the toe. The patient's general condition was good, and she felt well in herself. On that day the dector saw the pathological report, which showed the presence of Staphylococcus aureus resistant to tetracycline and Streptococcus pyogenes. He decided to continue the five-day course of tetracycline without prescribing any further drugs, and on 17 October, after that course had ended, he decided not to prescribe any further drugs. The finger and toe had virtually healed, and in his view "it was all over bar the shouting."

On 19 October the patient was discharged. She had a pain in her abdomen shortly before she went home, and at home she became ill and was treated by the doctor's partner and later by the defendant, who removed her to hospital,

1 Brit. med. F., 1967, 3, 624.

The Times, 9 May 1968. where a diagnosis of fulminating septicaemia was confirmed. The organism was identified as Str. pyogenes.

The trial judge held ${ }^{1}$ that the doctor was not guilty of negligence in failing to treat his patient's finger when it was first shown to him, or in failing to change the antibiotic to penicillin after seeing the pathologist's report. Despite the criticisms made by learned medical witnesses, the judge decided that the doctor's treatment in these respects was not negligent in the light of the experience found in Somerset in October 1963. But the judge accepted the opinion of a consultant bacteriologist that the administration of antibiotics ought not to have been discontinued after 16 October, despite the evidence of a consultant obstetrician and two general practitioners, who said that they would or might have done the same thing.

The Court of Appeal accepted and agreed with this decision. Lord Denning said that much depended on the state of the finger on 16 October. A nursing report had referred to the toe as being still moist and to one core having come out of the finger. Lord Denning appeared to be influenced by the failure to call evidence of the matron and nursing sister, who had been in court at the trial. The judge held that on 17 October the lesions were not fully healed, and the Court of Appeal agreed. The Court of Appeal dismissed the doctor's appeal, but allowed the patient's appeal as to amount, and increased damages from $£ 2,500$ to $£ 4,000$.

The standard of care required of a doctor by the law has been the standard of the doctor of ordinary competence of equivalent qualifications and pretensions to skill. The Court of Appeal in the present case purported to apply this same standard. The doctor, said Lord Denning, was to be judged as a general practitioner with a diploma in obstetrics. According to the report in The Times² Lord Denning said that-

"A charge of professional negligence against a medical man was serious. It stood on a different footing to a charge of negligence against the driver of a motor car. The consequences were far more serious. It affected his professional status and reputation. The burden of proof was correspondingly greater. As the charge was so grave, so should the proof be clear.

"With the best will in the world, things sometimes went amiss in surgical operations, or medical treatment. A doctor was not to be held negligent simply because something went wrong. He was not liable for mischance or misadventure ; or for an error of judgement. He was not liable for taking one choice out of two or for favouring one school rather than another. He was only liable when he fell below the standard of a reasonably competent practitioner in his field so much so that his conduct might be deserving of censure or inexcusable."

Yet it is not clear on what grounds the courts found themselves able to make a finding of negligence despite the evidence of competent doctors that they would have done the same as the defendant. It may be that the courts considered that the witnesses' answers to a hypothetical question were unconsciously influenced by sympathy for a fellow doctor, but the courts did not say so. Or it may be that the courts thought that their evidence was founded on an assumed set of facts which differed from the judicial findings of fact. Or it may be that the courts failed to pay the regard which they ought to have paid to that evidence, and were themselves swayed by sympathy for the patient's misfortunes. Lord Justice Diplock said that he had at times thought that the judge might have been recognizing a higher standard of prescience than was required of a general practitioner, though he agreed with Lord Denning. But Lord Justice Diplock 
continued by expressing sympathy for the doctor, "who was lulled into a sense of security as other general practitioners might have been by the normal effects of antibiotics" [our italics]." This comment, and particularly the words in italics, suggest that Lord Justice Diplock, and perhaps the other members of the Court of Appeal, may, despite protestations to the contrary, have been expecting of the doctor a standard of conduct higher than that shown by the ordinary obstetrically qualified general practitioner in Somerset in 1963.

The decision is unsatisfactory in its application of law to the facts of the case, though no substantial departure has been made from the accepted law on the subject, and the decision does not set a precedent for a change in the law. It is to be hoped that this approach to the facts will not be imitated in other cases in the future. It need not be.

\section{Mysteries of Membranes}

It was clear from the insight of Claude Bernard that membranes have a special role in maintaining a constant internal environment in cells. Later, neuromuscular excitation was shown to follow from the electrical properties of cell membranes, being specifically associated with movement of sodium and potassium ions across them. A few pioneers assembled information about the chemical composition and permeability of membranes. But progress was slow, and most biochemists were content to break up cells, identify enzymes carrying out individual reactions, and then purify and characterize them. Biophysicists were concerned either with electrophysiology or the structure of biological macromolecules. Because of their chemical and structural complexity, membranes were considered largely in terms of simplified models such as the bimolecular leaflet of J. F. Danielli and H. Davson. ${ }^{1}$

During the past decade membranes have attracted more and more attention. Enzymologists have come to appreciate that the spatial relationships of enzymes to one another and to membrane lipids are functionally important, as in oxidative phosphorylation in mitochondria. The variety of materials labelled with radioactive isotopes now available has made possible detailed studies of transport of organic compounds as well as ions across membranes, and membrane transport has been associated with a group of enzymes breaking down adenosine triphosphate and so liberating energy. Special methods have facilitated the recovery of membrane fractions from cells, and their composition has been studied by modern analytical techniques, including thin-layer and gas chromatography. The application of biophysical techniques such as electronmicroscopy, $x$-ray diffraction, and spectrophotometry have provided new insight into the structure of membranes.

Much of the contemporary work is conveniently summarized in the latest number of the British Medical Bulletin. ${ }^{2}$ Three articles are concerned with the chemical composition and organization of membranes. A. D. Bangham and D. A. Haydon discuss the arrangement of membrane constituents, with special reference to the ingenious model system of spherulites they have devised. These consist of onion-like concentric lamellae of phospholipid enclosing radioactively labelled ions ; the permeability of different ions through the

1 Danielli, J. F., and Davson, H., f. cell. comp. Physiol., 1935, 5, 495. 2 "Structure and Function of Membranes," Brit. med. Bull., 24, No. 2, May 1968. Medical Department of the British Council. $£ 2$.

Mac. nat. Acad. Sci. (W ash.) $1966,56,1552$. layers is remarkably similar to that through biological membranes, and effects of drugs on the model system can easily be analysed. J. A. Lucy discusses the possibility that lipids may in many membranes be organized in micelles (or colloidal aggregates) rather than in bimolecular leaflets, and that reversible transitions from one to the other are important in physiology and pathology. These two are the only plausible models if it is accepted that membrane proteins and lipids are segregated into discrete phases. However, this is an age of desegregation, and American authors have recently presented evidence that the hydrophobic groups of membrane proteins are intimately associated with the lipids, so that many membranes should be regarded as complexes rather than as consisting of discrete phases. ${ }^{3}$

Several contributors to the Bulletin discuss permeability across membranes of cells and of organelles such as mitochondria. P. F. Baker gives an excellent account of ion permeability in relation to nervous conduction. J. T. Dingle describes vacuoles, vesicles, and lysosomes, and their role in intracellular digestion. One remarkable property is the fusion of the membranes of different organelles, and also fusion with the plasma membrane, which Dingle considers analogous to the breakdown of foams.

Many drugs exert their effects on membranes, and A. C. Allison presents some generalizations about the physicochemical properties of drugs that are relevant to their interaction with membranes. It is astonishing how ignorant we still are of some such basic interactions-for instance, the mode of action of general anaesthetics.

Medical readers will be especially interested in the article by R. R. A. Coombs and P. J. Lachmann on immunological reactions at the cell surface. These range from simple agglutination to the complex sequence of events in complement fixation. Many other well-known phenomena, including anaphylaxis, immune adherence, effects of cytophilic antibody, and even recognition of antigen by antibodyproducing cells, depend on immunological reactions at cell membranes, which can trigger off a variety of responses within the cells. Immunological studies are also important in elucidating membrane structure itself. In general, this number of the British Medical Bulletin shows the active state of contemporary research on membranes and how much promise it holds for the future.

\section{Meeting at Cheltenham}

For its Annual Clinical Meeting this year the British Medical Association is being joined by the British Paediatric Association at Cheltenham on 24-27 October. As will be seen from the provisional programme published in the Supplement, a variety of clinical subjects are to be discussed, and, as is customary at these meetings, the emphasis is on matters of everyday concern to the doctor in his practice. Among them are virus diseases, allergic reactions in the lungs, malabsorption syndromes, and a variety of special topics in paediatric medicine. Attractive visits have also been arranged to places of interest in the neighbourhood and are tactfully listed under the heading "Ladies' Programme." Cheltenham itself is a spa town in beautiful country at the western edge of the Cotswolds with some fine Regency houses. A warm welcome invariably awaits the visitor to one of these clinical meetings, and this occasion will have the interest in addition of coinciding with the centenary of the Gloucestershire Branch of the B.M.A. 